\title{
ANTIMICROBIAL ACTIVITIES OF ENDOPHYTIC FUNGI ISOLATED FROM THREE ETHNO-MEDICINAL PLANTS OF ASSAM
}

\section{Rajreepa Talukdar ${ }^{1}$ and Kumananda Tayung ${ }^{1 *}$}

'Department of Botany, Gauhati University

Gopinath Bordoloi Nagar, Jalukbari, Guwahati-781014, Kamrup(M), Assam

*email id- kumanand@gauhati.ac.in (corresponding author), rajreepatalukdar@gmail.com

\begin{abstract}
Endophytic fungi were isolated from healthy leaf tissues of three ethno-medicinal plants of Assam, namely, Houttuynia cordata, Eryngium foetidum and Zanthoxylum oxyphyllum which are widely used in folk medicine to treat various ailments. Endophytic fungi were isolated from the surface sterilized leaves of the three plants cultivated using three different types of solid agar media. A total of 214 endophytic fungal isolates were isolated from all of the three plants belonging to 12 different genera. Maximum number of endophytic fungal isolates was recovered from $E$. foetidum (84), followed by $Z$ oxyphyllum and minimum was recovered from $H$. cordata (56). The most dominant fungal genus was found to be that of Colletotrichum with 107 isolates, followed morphotypes of by Mycelia Sterilia (69) and recovered from all of the three plants studied. Antimicrobial activity assay of the crude secondary metabolites extracted from the endophytic fungal isolates was performed using agar cup diffusion method. It revealed that 10 of the fungal species showed significant activity against all the test pathogens in varying degrees. Among all the isolates, endophytic fungi Colletotrichum coccodes and $C$. siamense showed maximum significant antimicrobial activity followed by other potent isolates like C. gleosporioides, Fusarium oxysporum, Curvularia sp., Penicillium sp., Scopulariopsis sp. and Cladosporium fulvum. The study thus indicated that the ethno-medicinal plants of Assam are colonized by a diverse range of endophytic fungi with prominent antimicrobial activity. Future investigation in this field would aid in the development of novel pharmaceutical agents.
\end{abstract}

Keywords: Ethno-medicinal Plants, Endophytic Fungi, Antimicrobial, Metabolites. 


\section{Introduction}

Medicinal plants have been used in the traditional folk medicines of India since ancient times. The indigenous tribal communities of developing countries including India have been using locally available medicinal plants for the treatment of various diseases. The compounds produced by these plants are nowadays even used in development and production of commercial drugs. According to estimates by the World Health Organization (WHO), about $80 \%$ of the world's population from developing countries depend largely on traditional plant derived medicines for primary health care. This has resulted in prominent scientific discoveries on a number of plant extracts and their biological activities. But due to the over exploitation of these bioresources, many plants used in traditional as well as commercial medicines have become critically endangered or are in verge of extinction. As such, search for alternative sources of effective antimicrobial drugs is the basic need in the recent times. One such unexplored yet environmental friendly source is endophytic fungi. Endophytic fungi are defined as those fungi that colonize healthy tissues of plants for a part or complete life cycle without causing any evident disease symptoms in their host (Petrini, 1991). Recently, quite a lot of study has been carried out on the role of endophytes in host plants which indicates their plant growth promoting activities, disease resistance attributes, improving plant's ability to withstand abiotic stresses as well as nutrient recycling (Sturz and
Nowak, 2000). In addition to these, endophytic fungi are also recognized as rich sources of bioactive metabolites that are of immense importance (Tan and Zou, 2001). However, it has been recently observed by various researchers that fungal endophytes inhabiting the medicinal plants could also produce metabolites similar to or with more activity than that of their respective hosts (Strobel, 2002). It is therefore considered that search for novel compounds should include plants commonly used by the local indigenous tribal population for medicinal purposes. The medicinal plants growing in exclusive or endemic locations are anticipated to harbor novel endophytes that may produce distinct metabolites with diverse importance (Strobel and Daisy, 2003). Assam being a highly diverse region of North East India is home to a number of endemic and locally used medicinal plants which could harbour potent endophytic fungi producing prominent antimicrobial metabolites. As it is believed that these plant species may harbor quite distinct and potential fungal endophytes producing novel metabolites, the present study was conducted to isolate and screen microbes of some medicinal plants widely used by the local ethnic tribal communities in a quest for discovery of novel metabolites.

\section{Materials and Methods}

\section{Plant sample collection}

Plant samples for the isolation of endophytic fungi were collected from 
different parts of Assam depending upon their abundance and usage by the tribal community as a source of traditional medicine. Five individual plants were selected and the healthy leaves were collected for each of the plant species were collected from each of the sites. The sample plants were brought in polythene bags and brought to the laboratory for further processing to isolate endophytic fungi.

\section{Isolation of endophytic fungi}

For isolation of endophytic fungi, the leaf samples were washed thoroughly under running tap water followed by washing with a mild bio-detergent and distilled water to remove the surface debris. For isolation of endophytic fungi, leaves of each plant species were surface sterilized following standard protocols with minor modifications (Tayung and Jena, 2013). The leaves were surface sterilized by sequentially dipping the leaf samples in $70 \%$ ethanol for 2-3 $\mathrm{min}$, then in $0.5 \%$ sodium hypochlorite for 1-2 min and finally rinsed with sterile distilled water. Upon drying under sterile conditions, the leaves were then punched into circular fragments of about $0.5 \mathrm{~mm}$ diameter using a sterile paper puncture. Sterilized fragments were inoculated on three different media; Potato Dextrose Agar (PDA) medium, Malt Extract Agar (MEA) medium and Water Agar (WA) medium, supplemented with streptomycin sulphate $(50 \mu \mathrm{g} / \mathrm{ml})$. Plates were then allowed to incubate at $25 \pm 2^{\circ} \mathrm{C}$ for about 2 weeks. Once fungal hyphae were found growing out of the surfaced sterilized leaf tissues, they were immediately transferred to PDA slants and stored at $4^{\circ} \mathrm{C}$ for further study.

\section{Identification of isolated endophytic fungi}

The fungal isolates found growing from the leaf tissues were identified based on their morphological and microscopic characters by growing on PDA medium referring standard identification manuals (Gilman 1971, Barnett and Hunter, 1996). Endophytic fungal isolates that failed to sporulate were designated as morphotypes under Mycelia sterilia.

\section{Secondary metabolite extraction}

Actively growing pure cultures of the fungal isolates were cultivated in Potato Dextrose Broth (PDB) in Erlenmeyer flasks and were incubated in $B O D$ shaking incubator for $2-3$ weeks at $28^{\circ} \mathrm{C}$ with a periodic shaking of $120 \mathrm{rpm}$. The culture was then filtered through sterile Whatmann filter paper to remove the fungal cell mass and the liquid broth was then collected. Equal volume of ethyl acetate was added to the liquid broth in a separating funnel and the metabolites were extracted by vigorous shaking for about 10-15 min. Residual fungal cell mass was thus separated and the solvent obtained was collected. The ethyl acetate was allowed to evaporate in a rotary evaporator and the resultant compound was dried with $\mathrm{MgSO}_{4}$ and concentrated to yield the crude extracts. Resultant crude extract was then dissolved in Dimethyl Sulphoxide (DMSO) and stored at $4^{\circ} \mathrm{C}$ to determine their antimicrobial activity.

\section{Screening for antimicrobial potential}


Antimicrobial activity of the crude extracts was determined by agar cup diffusion method against some clinically significant human test pathogens. The test pathogens include one gram positive bacterium, Staphylococcus aureus (MTCC 737), two gram negative bacteria, Pseudomonas aeruginosa (MTCC 424), Escherichia coli (MTCC 443) and one pathogenic fungus Candida albicans (MTCC 227). The test pathogens were obtained from Institute of Microbial Technology (IMTECH), Chandigarh, India.

Nutrient agar and Sabouraud's agar plates were inoculated with $0.2 \mathrm{ml}$ of test bacterial and fungal cultures respectively containing approximately $1.0 \times 10^{6}$ cells. The test pathogenic cultures were evenly spread out over the plates with the help of a sterile cotton swab. Agar cups were prepared in the plates using a cork borer and filled with $100 \mu \mathrm{L}$ of the crude extracts of endophytic fungi and incubated at $37 \pm 1^{\circ} \mathrm{C}$ for $24 \mathrm{hr}$ for bacterial and at $28 \pm 1^{\circ} \mathrm{C}$ for $48 \mathrm{hr}$ for fungal pathogens. Antimicrobial activity was determined on appearance of clear zones around agar cup against the target organisms. DMSO was used as the negative control and Streptomycin sulphate was used as the positive control.

Table 1. Ethno-medicinal plant species selected with their medicinal properties

\begin{tabular}{|c|c|c|c|}
\hline Name of plant & Family & Vernacular & Medicinal Properties \\
\hline Houttuynia cordata & Soururoce & $\begin{array}{l}\text { Musundari, } \\
\text { Musandari }\end{array}$ & $\begin{array}{l}\text { Anti-cancer, anti-viral, anti- } \\
\text { inflammatory, anti-microbial, } \\
\text { anti-allergic, anti-dysenteric }\end{array}$ \\
\hline Eryngium foetidum & Apiaceae & $\begin{array}{l}\text { Ban dhania, } \\
\text { Maan dhania }\end{array}$ & $\begin{array}{c}\text { Against constipation, asthma, } \\
\text { stomachache, antihelmenthic, } \\
\text { diarrhoea and malaria }\end{array}$ \\
\hline Zanthoxylum oxyphyllum & Rutaceae & $\begin{array}{c}\text { Mezenga, } \\
\text { Mejenga, Onger }\end{array}$ & $\begin{array}{l}\text { Stimulant, anti-diarrhoeaic, } \\
\text { anti-dysenteric, carminative, } \\
\text { rheumatism, arthritis }\end{array}$ \\
\hline
\end{tabular}


Table 2. Endophytic fungi isolated from leaf tissues of three ethno-medicinal plants of Assam

\begin{tabular}{|c|c|c|c|c|}
\hline $\begin{array}{l}\text { Genus of } \\
\text { endophytic fun }\end{array}$ & H. cordata & E. foetidum & Z. oxyphyllum & Total \\
\hline Colletotrichum & 21 & 48 & 38 & 107 \\
\hline Curvularia & 3 & 0 & 10 & 13 \\
\hline Bipolaris & 1 & 0 & 0 & 1 \\
\hline Corynespora & 2 & 0 & 2 & 4 \\
\hline Fusarium & 0 & 0 & 3 & 3 \\
\hline Aspergillus & 0 & 0 & 2 & 2 \\
\hline Scopulariopsis & 0 & 1 & 0 & 1 \\
\hline Cladosporium & 0 & 5 & 0 & 5 \\
\hline Stemphylium & 0 & 6 & 0 & 6 \\
\hline Penicillium & 0 & 1 & 0 & \\
\hline Alternaria & 0 & 2 & 0 & 2 \\
\hline Mycelia srterilia & 29 & & 19 & \\
\hline Total & 56 & 84 & 74 & 214 \\
\hline
\end{tabular}


Table 3. Antimicrobial activities of crude metabolites obtained from some of the potent endophytic fungal isolates

\section{Zone of inhibition}

\begin{tabular}{|c|c|c|c|c|}
\hline Endophytic fungi & $\begin{array}{l}\text { Candida } \\
\text { albicans }\end{array}$ & $\begin{array}{l}\text { Escherichia } \\
\text { coli }\end{array}$ & $\begin{array}{l}\text { Staphylococcus } \\
\text { aureus }\end{array}$ & $\begin{array}{l}\text { Pseudomonas } \\
\text { aeruginosa }\end{array}$ \\
\hline Colletotrichum coccodes & +++ & +++ & +++ & +++ \\
\hline Colletotrichum siamense & +++ & +++ & +++ & +++ \\
\hline Colletotrichum gloeosporioides & ++ & ++ & + & ++ \\
\hline Colletotrichum fructicola & + & + & ++ & - \\
\hline Curvularia sp. & ++ & + & ++ & + \\
\hline Penicillium sp. & + & TT & ++ & ++ \\
\hline Scopulariopsis sp. & + & & & ++ \\
\hline Cladosporium fulvum & & & & \\
\hline Fusarium oxysporum & +++ & & + & ++ \\
\hline Morphotype sp.10 & & & +++ & +++ \\
\hline
\end{tabular}

"_" indicates no inhibition; "+" indicates zone diameter > $10 \mathrm{~mm}$; “++" indicates zone diameter > $15 \mathrm{~mm}$;

“+++" indicates zone diameter $>20 \mathrm{~mm}$.
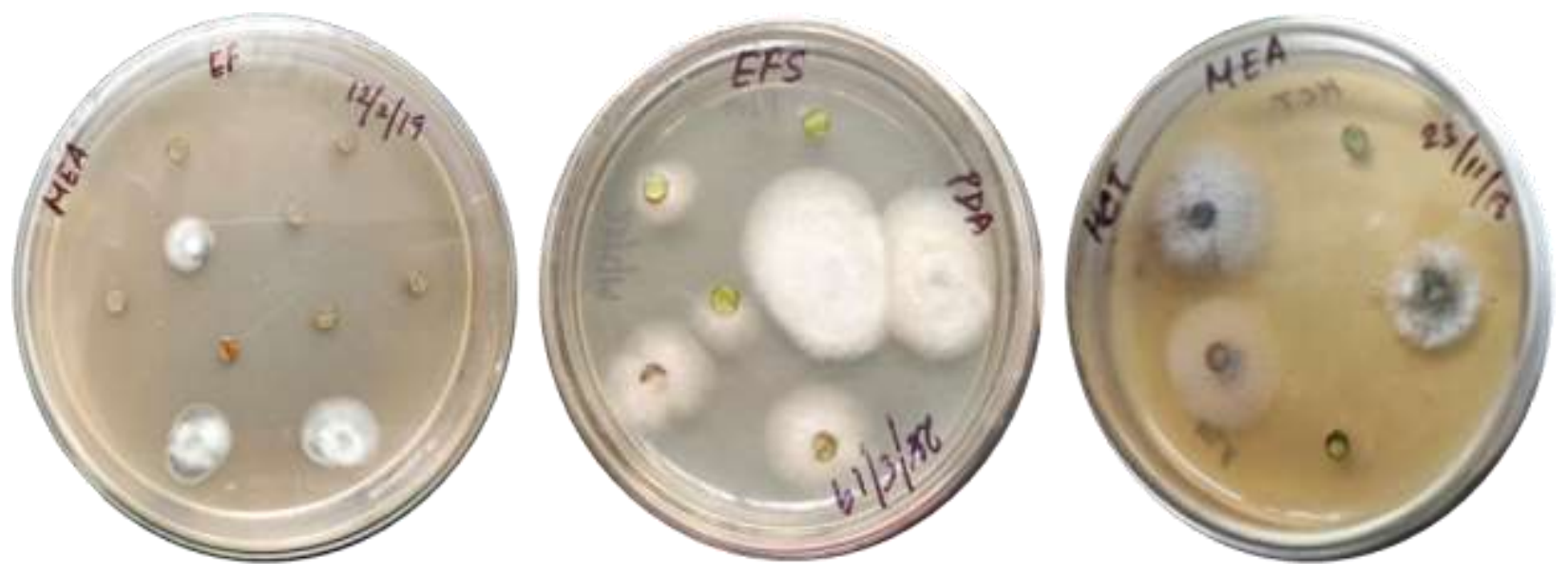

2020 November Edition | www.jbino.com | Innovative Association 
Figure 1. Endophytic fungi growing out from the leaf fragments of the selected medicinal plants

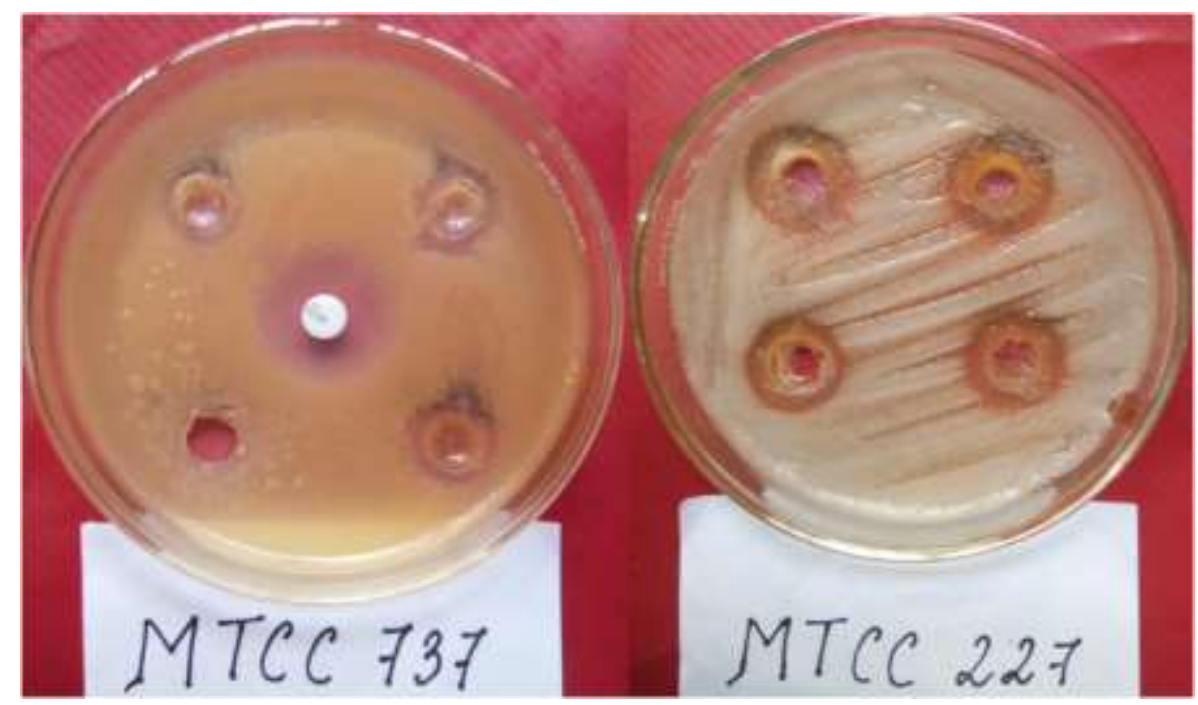

Figure 2. Antimicrobial activity of crude metabolites of some potent endophytic fungal isolates against test pathogenic microorganisms

\section{Results and Discussion}

Endophytic fungi are omnipresent in nature and known to be distributed globally in every plant species. Most of the endophytic fungi are reported to be associated with medicinal plants. Medicinal plants host numerous endophytic fungi that are involved in the co-production of active metabolites (Alvin et al., 2014). Also, India being a hub to a variety of medicinal plants and a mega biodiversity hotspot can be considered as a bio-resource site for obtaining novel metabolites from the endophytic fungi from its medicinal plants. Keeping this in mind, three potential medicinal plants used by the local ethnic tribal communities of Assam were selected for the present study (Table 1).
Endophytic fungi associated with the three selected ethno-medicinal plants of Assam in North-East India were investigated for their antimicrobial potential. Leaf tissues of the considered plant species were found to be colonized with a large number of endophytic fungi (Figure 1). A total of 214 endophytic fungal strains belonging to 12 genera were isolated from surface sterilized leaf fragments of all the three plants. Maximum isolates were obtained from the leaves of the plant E. foetidum (84), followed by $Z$. oxyphyllum (74) and the least was isolated from $\mathrm{H}$. cordata (56) (Table 2). Of the three different mycological media used for the isolation, namely potato dextrose agar (PDA), malt extract agar (MEA) and water agar (WA), the maximum recovery of endophytic isolates were obtained from PDA medium. 
Colonization of endophytes was found to be variable in the three medicinal plants.The endophytes consisted of fungi belonging to genera Colletotrichum, Fusarium, Aspergillus, Curvularia, Scopulariopsis, Bipolaris, Corynespora, Stemphylium, Penicillium, Cladosporium, Alternaria and non-sporulating fungi categorized as Mycelia Sterilia (Table 2). Endophytic fungi found to be dominantly occurring in all the three plants belonged to the genus Colletotrichum with a total of 107 isolates followed by morphotypes of Mycelia Sterilia that consisted of 69 isolates (Table 2). Several isolates belonging to the genus Colletotrichum were found to be commonly isolated from all of the three plants. This collides with earlier reports of Colletotrichum being one of the most dominant endophytic fungi isolated usually from medicinal plants (Siqueira et al., 2011; John and Mathew, 2017). Other fungal isolates found to be common in all the three species belonged to Mycelia Sterilia. Species of Curvularia and Corynespora were isolated from both H.cordata and Z. oxyphyllum. Fungal endophytes are reported to be host specific and several species can also be isolated from different host at the same time (Suryanarayanan et al., 2002). Similar host specific endophytic fungi have also been found to be isolated in our present study from the three medicinal plants.

Crude secondary metabolites extracted from fungal endophytes isolated from the three medicinal plants showed substantial antimicrobial activity against a panel of human test pathogenic microorganisms (Figure 2). Out of the all fungal endophytes isolated, 11 isolates could display antimicrobial activity inhibiting at least one of the test pathogens and 10 isolates displayed antagonistic activity against all the test pathogens (Table 3). Highest antimicrobial potential was shown by Colletotrichum coccodes and $C$. siamense as it displayed maximum zones of inhibition followed by $C$. gleosporioides against all the test bacteria and fungus. In quite a many instances, Colletotrichum sp. isolated from medicinal plants has been reported to confirm antimicrobial activity against numerous pathogenic microbial strains. The results thus collaborate with the findings of many previous workers (Zou et al., 2000; Gond et al., 2012). Isolates like Curvularia sp., Penicillium sp., Scopulariopsis sp. and Cladosporium fulvum also were found to inhibit the pathogenic test microorganisms. Promising antimicrobial activity has been reported earlier from endophytic Cladosporium species (Wang et al., 2007). Crude metabolite of an endophytic fungus identified as Fusarium oxysporum also displayed considerable antimicrobial activity against all the test pathogens. Fusarium has been reported as endophytic fungi from a number of plants (Mahesh et al., 2005; Nalini et al., 2005) and it has been stated to be a potent antimicrobial fungus against a broad range of microorganisms (Wang et al., 2007). Morphotype 10 and Morphotype 3 categorized under Mycelia Sterilia were also found to exhibit significant activity against all the test organisms. Thus it has been observed by the present investigation that the ethno-medicinal plants of Assam are a host to a number of endophytic fungus that produce potent 2020 November Edition | www.jbino.com | Innovative Association 
antimicrobial secondary metabolites. These metabolites upon characterization could be sources of various novel sources of antimicrobial agents that would have immense therapeutic applications.

\section{Acknowledgements}

The authors are grateful to the department of Botany, Gauhati University for providing with all the basic laboratory facilities and the taxonomists of Gauhati University Botanical Herbarium (GUBH) for helping with identification of the plant species used in the study.

\section{References}

Alvin, A., Miller, K.I., Neilan, B.A. (2014). Exploring the potential of endophytes from medicinal plants as sources of antimycobacterial compounds. Microbiol Res, 169(7-8),483-95.

Barnett, H.L., Hunter, B.B. (1996). Illustrated genera of imperfect fungi. APS Press.

Gilman, J.C. (1971). A manual of soil fungi. 2nd edition. lowa State College Press.

Gond, S.K., Mishra, A., Sharma, V.K., Verma, S.K., Kumar, J., Kharwar, R.N., Kumar, A. (2012). Diversity and antimicrobial activity of endophytic fungi isolated from Nyctanthes arbor-tristis, a well-known medicinal plant of India. Mycoscience, 53,113-21.

John, R., Mathew, L. (2017). Endophytic fungal assemblage in Achyranthes aspera Linn. revealed by internal transcribed spacer region of nuclear ribosomal RNA genes. 3 Biotech, 7(2), 109.
Mahesh, B., Tejesvi, M.V., Nalini, M.S. and Prakash, H.S. (2005). Endophytic mycoflora of inner bark of Azadirachta indica. A. Juss. Current Science, 88, 218-219.

Nalini, M.S., Mahesh, B., Tejesvi, M.V., Prakash, H.S. (2005). Fungal endophytes from the three-leaved caper, Crataeva magna (Lour.) DC.(Capparidaceae). Mycopathologia, 159, 245.

Petrini, O. (1991). Fungal endophytes of tree leaves in Microbial Ecology of Leaves (Eds: J. A. Andrews, S. S. Hirano). SpringerVerlag, New York, 179.

Siqueira, V.M., Conti, R., Araujo, J.M., Souza-Motta, C.M. (2011). Endophytic fungi from the medicinal plant Lippia sidoides Cham. and their antimicrobial activity. symbiosis, 53, 89-95.

Stobel, G.A, Daisy, B. (2003). Bioprospecting for Microbial Endophytes and Their Natural Products. Microbiol Mol Biol Rev, 67, 491-502.

Strobel, G.A. (2002). Rainforest Endophytes and Bioactive Products. Crit. Rev. Biotechnology, 22, 315.

Sturz, A.V., Nowak, J. (2000). Endophytic communities of Rhizobacteria and the strategies required creating yieldenhancing associations with crops. Applied Soil Ecology, 15, 183.

Suryanarayanan, T.S., Murall, T.S., Venkatesan, G. (2002). Occurrence and distribution of fungal endophytes in tropical forests across a rainfall gradient. Canadian Journal of Botany, $80,818$. 
Tan, R.X and Zou, W.X. (2001). Endophytes: a rich source of functional metabolites. Nat. Prod. Rep, 18, 448-459.

Tayung, K., Jena, S.K.(2013). Endophytic fungal communities associated with two ethno-medicinal plants of Similipal Biosphere Reserve, India and their antimicrobial prospective. I Appl Pharm Sci, 3(4S-1), S7-17.

Wang, F.W., Jiao, R.H., Cheng, A.B., Tan, S.H., Song, Y.C. (2007). Antimicrobial potentials of endophytic fungi residing in Quercus variabilis and brefeldin A obtained from Cladosporium sp. World Journal of Microbiology and Biotechnology, 23, 79.

Zou, W.X., Meng, J.C., Lu, H., Chen, G.X., Shi, G.X., Zhang, T.Y., Tan, R.X.(2000). Metabolites of Colletotrichum gloeosporioides, an endophytic fungus in Artemisia mongolica. J Nat Prod, 2000, 63,1529-30. 